\title{
O PAPEL DO ESTÁGIO SUPERVISIONADO NA FORMAÇÃO DO PROFESSOR DE MATEMÁTICA: COM A PALAVRA, OS FUTUROS EDUCADORES
}

\author{
Fábio Alexandre Borges ${ }^{1}$ \\ Ariele Rodrigues Stirle²
}

\begin{abstract}
Resumo
Dentre os diversos aspectos que determinam o alto nível de complexidade que envolve a formação docente inicial, destacamos aqui a ausência de um diálogo maior entre a Educação Básica e o Ensino Superior. Essa falta de conexão fica mais evidente quando os futuros professores retornam para a Educação Básica na condição de estagiários, momento que se apresenta de grande potencial para uma análise dessa aproximação conexão entre o ambiente formativo e o profissional. Nesse texto, apresentamos uma pesquisa que buscou investigar quais aspectos são destacados em relatos de estágio por futuros professores de Matemática em formação inicial. O corpus da pesquisa consistiu em seis relatórios de estágio relativos à experiência de regência no Ensino Médio. Para a análise dos dados, utilizamos de elementos da Análise Textual Discursiva. Como resultados, elencamos e analisamos quatro categorias: infraestrutura do colégio onde cumpriram o estágio; a tentativa dos estagiários em implementar atividades ou condutas diferentes das adotadas pelos professores regentes da turma; a insegurança dos agentes escolares em admitir o estagiário como regente; e a necessidade da reestruturação dos cursos de Licenciatura em Matemática.
\end{abstract}

Palavras-chave: Estágio Supervisionado. Formação Inicial. Licenciatura em Matemática.

\section{THE ROLE OF THE STAGE SUPERVISED IN THE TRAINING OF THE MATH TEACHER: WITH THE WORD, THE FUTURE EDUCATORS}

\begin{abstract}
Among the various aspects that determine the high level of complexity involved in initial teacher training, we highlight here the absence of a greater dialogue between Basic Education and Higher Education. This lack of connection is more evident when the future teachers return to Basic Education as trainees, a moment that presents great potential for an analysis of this approximation connection between the training environment and the professional. In this text, we present a research that sought to investigate which aspects are highlighted in reports of traineeship by future teachers of Mathematics in initial formation. The corpus of the research consisted of six internship reports related to the regency experience in High School. For the

\footnotetext{
1 Possui graduação em Licenciatura Plena em Matemática pela Universidade Estadual de Maringá (2002), Mestrado pelo Programa de Pós-graduação em Educação para a Ciência e a Matemática (2006) da Universidade Estadual de Maringá e Doutorado pelo mesmo Programa (2013). Atualmente, realiza estágio pós-doutoral na Universidade Estadual de Londrina, pelo Programa de Pós-graduação em Ensino de Ciências e Educação Matemática.

2 Licenciada em Matemática pela Universidade Estadual do Paraná Campus de Campo Mourão (2018), Pós-graduada em Alfabetização Matemática pela Faculdade Unina (2020). Universidade
} Estadual do Paraná Campus de Campo Mourão; arielestirle@gmail.com
\end{abstract}


analysis of the data, we use elements of Discursive Textual Analysis. As results, we list and analyze four categories: the infrastructure of the college where they completed the internship; the attempt of the trainees to implement activities or behaviors different from those adopted by the regent teachers of the class; the insecurity of the school agents in admitting the trainee as regent; and the need to restructure degrees courses in Mathematics.

Keywords: Supervised internship. Initial formation. Degree in Mathematics.

\section{Introdução}

A formação inicial de professores vive sempre o dilema quanto à necessidade de buscar nexos e transversalidade entre os diferentes campos que historicamente dividiram as áreas. Por exemplo, nos cursos de formação em Matemática, temos disciplinas ditas de Matemática Pura, de Matemática Aplicada, de Ensino e outras. Essa falta de diálogo/aproximação estava nítida, por exemplo (se é que já conseguimos romper com isso), com o modelo de formação denominado " $3+1$ " (SAVIANI, 2009), que separava na grade curricular desses cursos apenas 1 ano, e o último, para discutir os aspectos de formação docente e profissional. Entendemos que o rompimento com essa prática já avançou, porém, ainda deixa resquícios, os quais precisam ser problematizados, não somente pelos documentos que regem os cursos, como também na prática.

Durante a formação inicial dos estudantes de licenciatura, o Estágio Supervisionado é o principal componente curricular com a finalidade de aproximar o futuro professor da prática docente e, na maioria das vezes, é somente por meio do estágio que o estudante tem esse primeiro contato. Para Teixeira e Santos (2017), essa primeira experiência com a prática docente possibilita ao licenciando desenvolver aspectos da sua identidade enquanto futuro professor, contribuindo para o desenvolvimento profissional do mesmo. Para Furtado et al (2017), o Estágio Supervisionado se configura como eixo central na formação inicial de docentes. Fazse necessário que essa etapa desenvolva seu papel na formação inicial do professor de Matemática. O objetivo da presente pesquisa consistiu em discutir o papel do estágio supervisionado na formação inicial do professor de Matemática. Ao tratar esse tema, há que se considerar os sujeitos envolvidos nesse processo, portanto, 


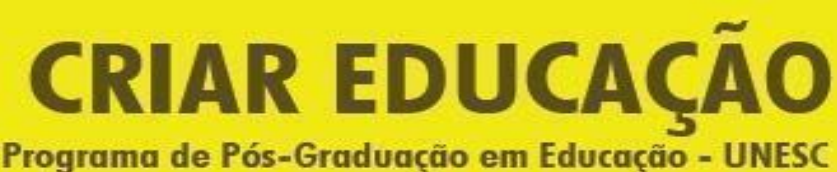

Revista do Programa de Pós-Graduação em Educação - UNESC

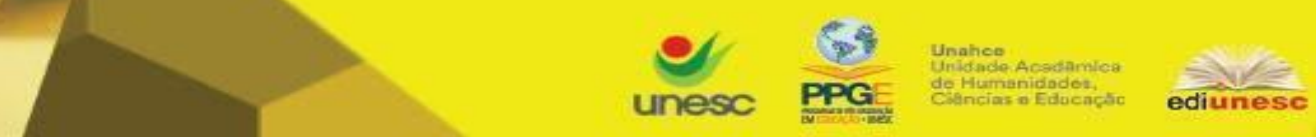

Criar Educação, Criciúma, v. 9, №2, Edição Especial 2020.- PPGE - UNESC - ISSN 2317-2452

levaremos em consideração o ponto de vista dos futuros professores enquanto estudantes de licenciatura em Matemática de uma instituição pública do Estado do Paraná, após vivenciar a prática docente ao cumprir o estágio, a fim de discutir, também, a necessidade de mudança/reestruturação do Estágio Supervisionado, assim como de toda a grade curricular.

Nesse sentido, o presente texto busca investigar quais aspectos são destacados em relatos de estágio por futuros professores de Matemática em formação inicial, ao se depararem com a experiência de Estágio Supervisionado.

\section{O papel do Estágio Supervisionado na formação inicial de professores de Matemática}

As recentes pesquisas brasileiras que compuseram o corpus da nossa Pesquisa Bibliográfica apontam o Estágio Supervisionado sob variados enfoques, tais como: componente curricular vinculado ao planejamento de aulas para a regência (TEIXEIRA; CYRINO, 2015); ambiente onde os sujeitos envolvidos produzem conhecimento através de suas interações (SILVA; CEDRO, 2015); espaço que possibilita a construção de conhecimentos docentes (SAKAl; PEREIRA, 2017); a vivência de situações desestabilizadoras e motivadoras (SOUZA; CHAPANI, 2016); o espaço no qual o licenciando se relaciona com a escola, a fim de desenvolver a prática docente, configurando-se como eixo central nos cursos de licenciatura (FURTADO et al, 2017), dentre outros. Discutiremos aqui algumas dessas abordagens, com as quais esperamos refletir em nossa análise dos dados, bem como contribuir com o leitor, no sentido de apresentar, ainda que resumidamente, um panorama das pesquisas brasileiras atuais com relação a essa temática.

Para Lopes et al (2017), o Estágio Supervisionado é compreendido como um ambiente essencial para o entendimento da complexidade da profissão e para a construção da identidade docente, sendo um dos componentes curriculares da formação inicial de professores destinado ao desenvolvimento da prática docente. Para os autores, é necessário reconhecer o Estágio Supervisionado como um ambiente de aprendizagens complementar à grade curricular. Assim, o mesmo deve 


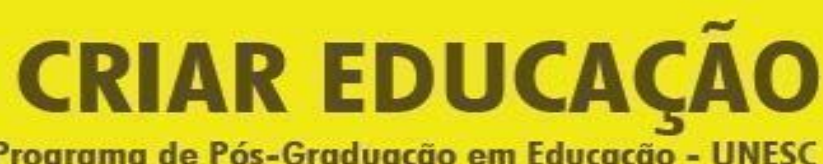

Revista do Programa de Pós-Graduação em Educação - UNESC

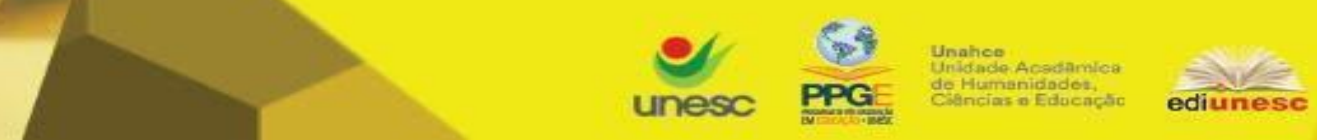

Criar Educação, Criciúma, v. 9, no2, Edição Especial 2020.- PPGE - UNESC - ISSN 2317-2452

estar presente em todo o processo de formação, com a finalidade de fazer a relação entre a teoria e a prática. Todavia, entendemos que não se pode relegar única e exclusivamente ao estágio o papel dessa aproximação teoria e prática, sendo que essa perspectiva deve se dar de maneira transversal em todos os momentos formativos, em todas as disciplinas, principalmente em um curso de licenciatura.

Conforme Saviani (2009), quando foram instituídos os cursos de licenciatura, adotava-se o modelo conhecido como " $3+1$ " para organizar os estudos, de modo que, em três anos estudavam-se as disciplinas específicas de cada curso, e um ano era voltado para formação didática, ou seja, a experiência com o Estágio Supervisionado acontecia somente no último ano de formação. Com isso, o autor aponta que esse modelo dava menor importância à formação didática e pedagógica, que passava a ser vista apenas como exigência para formar professores. Ainda que as matrizes curriculares possivelmente avançaram no sentido de diluir o modelo " $3+1$ ", a parte prática dos cursos de licenciatura ainda precisa ser modificada. Não basta uma redistribuição das disciplinas, sem que haja um diálogo entre elas, é preciso considerar o objetivo maior de formar futuros educadores. Nesse sentido, atividades interdisciplinares seriam uma alternativa possível, sempre aproximando os conhecimentos matemáticos com os pedagógicos.

Moreira (2012) afirma que a lógica do modelo $3+1$ ainda está presente na estrutura dos cursos de licenciatura, pois, as disciplinas de conteúdo específico e as disciplinas didático-pedagógicas continuam separadas e são independentes entre si. Segundo o autor, por volta de 1980 foi implementado um bloco de disciplinas que visava integralizar tais disciplinas, porém o resultado alcançado foram três blocos independentes que acabaram deixando ao licenciando a responsabilidade de organizar os saberes adquiridos durante a formação que são necessários para a prática docente. $\mathrm{Na}$ prática em sala de aula, os conteúdos matemáticos estão interligados com o ensino, portanto, o autor afirma que, ao separá-los no processo de formação, implica-se na não preparação do futuro professor para a prática docente. Com isso, ele propõe que, ao pensar a formação de professores de Matemática, devemos considerar a compreensão da prática, levando em conta a Matemática que o futuro professor vai ensinar na Educação Básica e os conhecimentos que são 


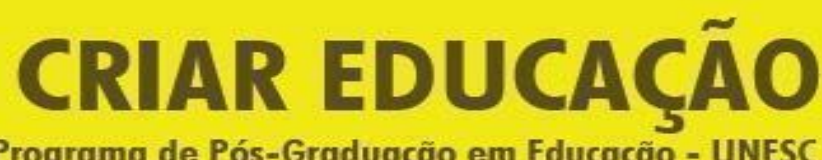

Revista do Programa de Pós-Graduação em Educação - UNESC

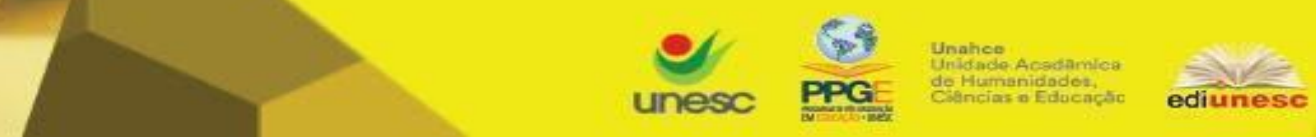

Criar Educação, Criciúma, v. 9, no2, Edição Especial 2020.- PPGE - UNESC - ISSN 2317-2452

necessários para ensiná-la, ou seja, é preciso repensar os cursos de Licenciatura em Matemática a partir dos saberes matemáticos.

Ao pensar em reestruturar os cursos de Licenciatura em Matemática, surgem alguns desafios a serem enfrentados. Para Moreira (2012), esses desafios se constituem em aprofundar os conhecimentos acerca da prática docente e outros aspectos que surgem durante a atuação em sala de aula, repensar a formação dos professores da graduação, pois, foram sujeitos do modelo $3+1$ e, consequentemente, não estão qualificados (na maioria das vezes) para integralizar as disciplinas de conteúdo específico com as disciplinas didático-pedagógicas. Como aponta o autor, ter competência como matemático não implica ter competência para formar futuros professores de Matemática. Entre os desafios citados pelo autor, também está o de promover pesquisas acerca do papel da Matemática ensinada durante a licenciatura na formação do futuro professor e organizar a Matemática necessária para a docência em materiais voltados para a formação de professores. Com isso, o autor afirma que é possível reestruturar os cursos de licenciatura de modo que formem melhor o futuro professor de Matemática.

As Diretrizes Curriculares Nacionais para os Cursos de Matemática, Bacharelado e Licenciatura definem que o professor de Matemática deve ser capaz de tomar decisões, refletir sobre sua prática docente, e perceber que a mesma é o espaço em que novos conhecimentos são formados e modificados. Sendo assim, o Estágio Supervisionado é essencial nos cursos de Licenciatura em Matemática, e deve possibilitar o desenvolvimento de ações nas quais o licenciando se torne responsável por tarefas cada vez mais complexas, e o desenvolvimento de uma aprendizagem monitorada por profissionais já em atuação (BRASIL, 2011).

Porém, da maneira como tem sido trabalhado, constituído de períodos de observação participativa e períodos de regência, e guiado, em certos momentos, por profissionais sem capacitação na área, o Estágio Supervisionado acabou tornandose, em alguns casos, uma reprodução de práticas observadas pelo acadêmico nos momentos em que está na condição de estudante (CRUZ; BITTAR, 2015), e quando não se promove uma reflexão acerca da prática docente vivida pelos licenciandos enquanto estagiários, o Estágio Supervisionado configura-se como uma atividade 
técnica e burocrática, perdendo sua importância na formação inicial de professores (SAKAI; PEREIRA, 2017). Com isso, essas duas últimas pesquisas aqui referenciadas promovem um debate acerca da necessidade de reestruturação do Estágio Supervisionado.

Sakai e Pereira (2017), ao estudar propostas de modelos de Estágio Supervisionado, apontam a urgente necessidade de valorizar a prática coletiva, permeada por interações e compartilhamento de saberes e experiências, e a prática reflexiva durante os períodos de estágio, pois, para as autoras, esses tipos de práticas favorecem o desenvolvimento profissional dos futuros professores, assim como, dos professores regentes. Cruz e Bittar (2015), a fim de romper o modelo como o Estágio Supervisionado tem sido trabalhado, constituído de períodos de observação participativa e regência, propõem o modelo Ensino Prático Reflexivo, baseado em Schön, com o objetivo de que o licenciando aprenda a prática docente através do fazer, seguindo orientações de um profissional experiente, pois, muitas vezes surgem conflitos durante a regência que não são percebidos pelo futuro professor, sendo necessária a intervenção do orientador de estágio. Para as autoras, quando o futuro educador reflete sobre sua prática docente, ele torna-se capaz de perceber os erros que cometeu e apontar caminhos para contornar tais situações. Deste modo, esse modelo proporciona ao licenciando uma reflexão a partir de conhecimentos teóricos e conhecimentos adquiridos durante a prática docente, fazendo integração entre a teoria e a prática, o que permite o futuro professor compreender os acontecimentos vividos em sua experiência enquanto estagiário, constituindo, assim, o Estágio Supervisionado em um momento de aprendizagem.

Quadros e Kochhann (2018) afirmam que os futuros professores precisam conhecer o ambiente em que irão atuar enquanto profissionais, para que possam integralizar teoria e prática e, consequentemente, construir saberes relativos à prática docente. Tais saberes docentes foram definidos pelas autoras em seis categorias: saberes experienciais (adquiridos e validados por meio da experiência), saberes disciplinares (adquiridos durante a graduação), saberes educacionais (relativos a política educacional estudada na graduação), saberes pedagógicos (relativos ao processo educativo, ao saber ensinar Matemática), saberes da imersão sociocultural 
(advém dos princípios e valores da comunidade escolar) e saberes da cultura profissional (compreensão do papel do professor). É por meio do Estágio Supervisionado que o licenciando entra em contato com o ambiente em que ele exerce sua profissão. Como aponta as autoras, o estágio permite que o licenciando experimente a prática docente e, com isso, possa se ver enquanto professor, mas a construção desses saberes essenciais à docência só acontece quando existe uma reflexão sobre esse momento de atuação.

Há de se considerar que existem fatores externos a graduação que interferem na qualidade da formação dos licenciandos. Ao cumprir o Estágio Supervisionado, algumas vezes os futuros professores se deparam com obstáculos relativos à precariedade na infraestrutura do ambiente escolar, laboratórios de informática com pouquíssimos computadores que funcionam e laboratórios de ensino com poucos recursos didáticos, dificultando que os estagiários implantem atividades diferenciadas que dependem desses recursos e, como aponta Monteiro e Silva (2015), a deficiência na infraestrutura escolar prejudica o processo de ensino e aprendizagem. Outro fator que restringe a construção de saberes por parte dos futuros professores é a pouca autonomia que Ihes é permitida durante o período de regência, o que vai contra o argumento de Tardif (2007) de que o estagiário precisa de tempo e espaço para atuar seguindo suas próprias práticas de ensino para, assim, construir os saberes necessários à docência.

\section{Procedimentos metodológicos}

Considerando que o corpus da presente pesquisa se trata de Relatos de Estágio Supervisionado II da Unespar/Campo Mourão, cabe aqui discorrer acerca de como ocorre o estágio na referida instituição e o papel desses Relatos. Na Unespar de Campo Mourão, o curso de Matemática oferta dois estágios supervisionados, totalizando 432 horas/aula. Tais aulas incluem a análise de documentos da escola, o cotidiano escolar, diferentes momentos do ambiente a ser estagiado, estudo de metodologias de ensino, debates acerca de fatos relacionados à regência e à observação das aulas. Quanto à entrada em sala de aula, os estudantes se organizam 
em duplas, sendo: 5 aulas de observação participativa (quando os estagiários assistem a professora regente em suas aulas e participam na medida do possível) e 20 aulas de regência (conduzidas pela dupla, porém, evitando sempre que um deles interfira no outro). Essa regência é avaliada tanto pelo professor da turma quanto pelo docente da disciplina de Estágio na Unespar. Como critério avaliativo, está garantido no Projeto Pedagógico do Curso que os acadêmicos devem redigir ao final de cada estágio (l e II) um Relatório, que contemple os principais aspectos de forma dissertativa. Dentre diversos temas, eles trazem: conteúdos trabalhados e dificuldades encontradas com a matemática; o relacionamento com os demais agentes da escola; a receptividade no ambiente escolar; o relacionamento com os estudantes e o colega de dupla de estágio; a estrutura física e organizacional da escola; as possíveis contribuições ou não da formação que a universidade promove com as necessidades que se explicitam nessa regência etc.

A presente pesquisa é de cunho qualitativo, na qual, inicialmente, fizemos uma Pesquisa Bibliográfica e, em seguida, uma abordagem relacionada à Análise Textual Discursiva. A escolha dessa metodologia deve-se a importância da Pesquisa Bibliográfica defendida por Pizzani et al (2012). Os autores apontam que esse tipo de pesquisa impulsiona o aprendizado e novas descobertas quando se trata de investigar o que já foi produzido em uma determinada área do conhecimento, no caso dessa pesquisa, o Estágio Supervisionado. Nessa etapa, atentamo-nos aos periódicos científicos com as seguintes características: que fossem qualificados pela Capes Coordenação de Aperfeiçoamento de Pessoal de nível Superior; que apresentassem publicação regular nos últimos três anos; e que fossem diretamente voltados para o campo de investigação em Educação Matemática. Além disso, usamos apenas periódicos online a fim de facilitar a busca pelos textos. Os textos selecionados continham a palavra "estágio" no título e abordavam o tema proposto por meio de pesquisas brasileiras. Com as leituras dos textos, buscamos discutir o papel do Estágio Supervisionado na formação inicial de futuros professores de Matemática.

Na sequência, fizemos a Análise Textual Discursiva de relatórios de Estágio Supervisionado escritos por estudantes do curso de Licenciatura em Matemática da Unespar - Campus Campo Mourão, que, convidados a participar dessa pesquisa, 
dispuseram seus textos para analisarmos. Esses relatórios referem-se à experiência dos futuros docentes que cumpriram Estágio Supervisionado II nos anos de 2015 e 2016. A escolha desse material para análise se deve ao fato de que, ao escrever o relatório de estágio, o licenciando explicita seu entendimento sobre a interação entre - Estágio Supervisionado e a prática docente como um componente curricular (VALERIO et al, 2016), e reflete sobre suas práticas em sala de aula durante o período de regência, pensando em suas futuras ações como professor e aprimorando sua prática docente (TEIXEIRA; SANTOS, 2017). Tais relatórios passaram pelo processo de Análise Textual Discursiva proposto por Moraes (1999), o qual se baseia em agrupar os dados considerando os aspectos comuns apresentados entre eles. $\mathrm{Ou}$ seja, buscamos elencar elementos comuns nos relatórios analisados, a fim de determinar, em seguida, as categorias de investigação, sendo que a Revisão Bibliográfica nos auxiliou na análise dessas categorias.

Consideramos para a análise seis relatórios, dos quais, cada um, foi desfragmentado, como proposto por Moraes (1999), em um processo de unitarização, ou seja, extraímos do texto os aspectos significativos de suas ideias, denominados por nós de unidades de significado. Os estagiários autores desses relatórios serão aqui denominados de E1 a E6. Com relação ao gênero sexual, bem como possíveis outras experiências desses sujeitos na condição de docência (para além dos estágios do próprio curso em questão), seguem algumas informações: E1 é do gênero feminino e já havia tido experiência em sala de aula no estágio do curso de Formação Docente, em nível de Ensino Médio; E2 é do gênero masculino e não havia tido outras experiências em sala de aula; E3 é do gênero masculino e foi bolsista do PIBID, com experiência de atuação participativa em sala de aula; E4 é do gênero masculino e, durante o desenvolvimento do Projeto de Iniciação Científica, teve a oportunidade de atuar em sala de aula para a aplicação de atividades; E5 é do gênero feminino e era professora substituta da Educação Básica desde o ano de 2011; por fim, E6 é do gênero feminino e também foi bolsista do programa PIBID.

Com as unidades de significado de cada sujeito definidas, buscamos escrever, para cada sujeito, a sua compreensão ideográfica, ou seja, o discurso já reunindo apenas as principais discussões do sujeito, livre de redundâncias e outras 


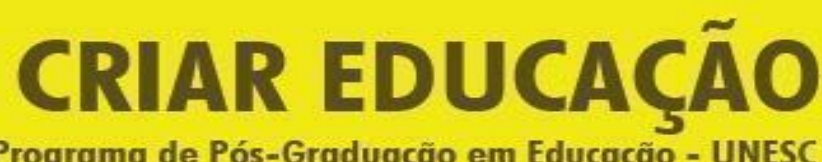

Revista do Programa de Pós-Graduação em Educação - UNESC

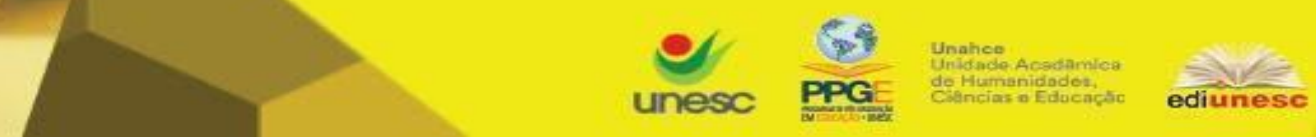

Criar Educação, Criciúma, v. 9, no2, Edição Especial 2020.- PPGE - UNESC - ISSN 2317-2452

características da fala do sujeito. Na sequência, agrupamos as unidades que discutiam aspectos semelhantes, constituindo, assim, as categorias de investigação, que nos permitiram traçar os principais aspectos destacados por futuros professores de Matemática em formação relativos ao papel do Estágio Supervisionado.

As categorias por nós elencadas foram: 1) infraestrutura do colégio onde cumpriram o estágio; 2) a tentativa dos estagiários em implementar atividades ou condutas diferentes das adotadas pelos professores regentes da turma; 3) a insegurança dos agentes escolares em admitir o estagiário como regente; 4) e a necessidade da reestruturação dos cursos de Licenciatura em Matemática. Tais aspectos serão discutidos nas categorias a seguir. Na sequência trazemos a análise dos dados. Da primeira parte, a descrição das ideias dos sujeitos, ilustraremos apenas com E6, considerando as limitações de espaço necessárias para a organização do texto na forma de artigo. Na sequência, discutimos cada uma das categorias.

\section{Análise dos dados}

\section{Descrição das ideias de E6}

\begin{tabular}{|l|}
\hline \multicolumn{1}{|c|}{ Perfil de E6 } \\
\hline Gênero sexual: Feminino \\
Experiências de ensino em sala de aula além dos estágios supervisionados: \\
Participou do Projeto Institucional de Iniciação à Docência - PIBID por um período \\
de dois anos, e fez estágio na Educação Infantil.
\end{tabular}

E6 descreveu o colégio começando pelo portão principal, constituído por duas grades de 2 a 3 metros de altura e uns 2 metros de largura, com fechadura eletrônica e sendo aberto apenas nos horários de entrada e saída dos alunos. Para E6, o que prevaleceu no colégio são as áreas de "concreto". O colégio contempla um laboratório de informática, com apenas alguns computadores que funcionam, e um laboratório de matemática. Ao falar da relação entre pais e professores, E6 disse que a única vez que percebeu a presença dos pais na escola foi na reunião de entrega dos boletins.

Segundo E6 não foi difícil conseguir permissão para estagiar nesse colégio, mas existiram transtornos. A diretora não foi simpática com as estagiárias.

As 5 aulas de observação deixaram E6 assustada pelo fato de que os alunos 


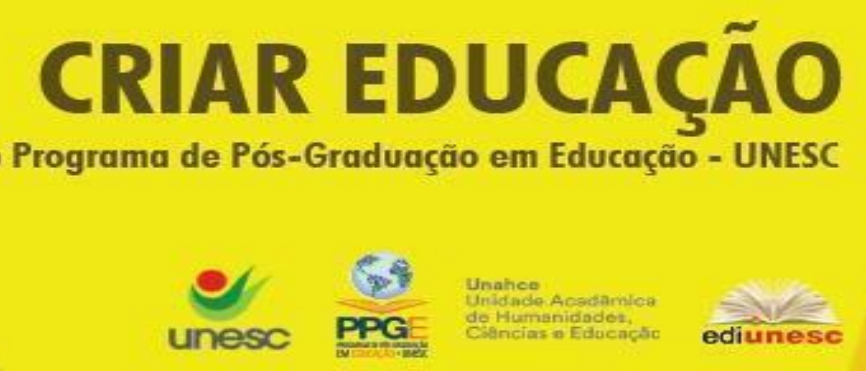

Criar Educação, Criciúma, v. 9, oㅡ, Edição Especial 2020.- PPGE - UNESC - ISSN 2317-2452

falavam alto, riam, conversavam, ouviam músicas e tiravam foto durante a aula. Segundo ela, houve uma mudança brusca para os alunos, já que o terceiro bimestre foi iniciado por um professor substituto e, em seguida, chegaram as estagiárias. A estagiária fez uma crítica ao fato de o professor regente ter elencado de uma única vez 17 fórmulas de relações trigonométricas para introdução do tema, o que, para ela, seria inadequado, havendo a necessidade de introdução do conteúdo de maneira diferenciada.

E6.US15: "[...] 17 fórmulas [de relações trigonométricas], o que a meu ver foi um absurdo [...]."

O professor regente não chamava a atenção dos alunos e, em determinados momentos, confundiu as estagiárias com estudantes da turma. E6 contou que os alunos não resolveram os exercícios propostos para o aprendizado das relações trigonométricas e o professor não insistiu para que o fizessem.

E6.US18: "[...] o professor confundir eu e minha parceira com alunas, este olhou para nossos rostos e disse: "vocês serão a dupla de número 1" [...]."

Neste dia de observação, as estagiárias interviram oferecendo ajuda aos alunos individualmente, explicando noções sobre seno e cosseno, e auxiliando os alunos a resolverem os exercícios. Após isso, os alunos as viram como uma espécie de "salvação", e relataram que o professor passava conteúdo, explicava, passava exercício e iniciava outro conteúdo.

Para E6, o professor regente teve dificuldades de se relacionar com a turma, sendo que sequer os cumprimentava com um "bom dia". Ao saber que o professor era formado em Engenharia Química, E6 criticou que Didática e Metodologia eram extintas da sua docência. A estagiária relacionou o problema de comportamento da turma à conduta do professor.

E6.US29: "Ele é o tipo de professor que contribuiu na formação da minha identidade docente no sentido de: não quero ser como você."

Segundo E6, durante a sua regência a autoridade pertencia ao professor, e os alunos as viam como estagiárias. Em um dos dias em que realizou sua regência, E6 identificou uma aluna nova na sala que, devido a problemas pessoais, estava afastada 
das aulas, sendo que o professor regente sequer notou a presença da mesma.

E6 desabafou que todos os dias quando chegavam ao colégio ficavam sentadas na sala de espera, pois nunca foram convidadas a entrar na sala dos professores. O professor regente passava por elas e não as cumprimentava.

O conteúdo definido para as estagiárias trabalharem foi Análise Combinatória e Probabilidade. E6 sabia que não dariam conta desse conteúdo em 20 aulas, sendo que, de fato, não conseguiram discutir Probabilidade. Antes de iniciar o conteúdo de Análise Combinatória, E6 precisou aprendê-lo, pois não havia discutido tal tema quando estudante do Ensino Médio e tampouco no Ensino Superior. Ela enfatizou que a faculdade ensinou pouquíssimos conteúdos que são trabalhados no Ensino Fundamental e Médio, afirmando que o curso de Licenciatura em Matemática está voltado para o Ensino Superior.

Quando iniciaram a regência, as estagiárias fizeram alguns acordos dialogados com os alunos. Dentre eles, seria proibido o uso de celular durante as aulas e conversas durante a explicação. As aulas de regência contaram com dinâmicas para introduzir os conteúdos, ideia que partiu do orientador de estágio. O professor regente deu liberdade para as estagiárias trabalharem da maneira como planejassem e definir os dias de provas e trabalhos. Segundo E6, o professor regente a interrompeu apenas uma vez para corrigi-la

Durante a regência, E6 e sua parceira de estágio se alternavam na condição de professor: enquanto uma explicava a matéria ou corrigia as atividades, a outra auxiliava na organização da sala e nas dúvidas dos alunos.

As estagiárias elaboraram um mapa conceitual com os alunos acerca da Análise Combinatória, pois temiam que eles não conseguissem identificar os diferentes tipos de problemas. Segundo E6, tal estratégia foi um sucesso, já que os alunos aprenderam a utilizar o mapa e utilizaram em uma atividade proposta.

Ao fazer a prova desse conteúdo, os alunos usaram o mapa conceitual e as fórmulas foram disponibilizadas. Com isso, a maior parte da turma alcançou a média acima de 6,0 nas avaliações de responsabilidade das estagiárias. Os alunos ficaram descontentes, pois a nota atribuída pelas estagiárias teve peso de $30 \%$ da nota total do 3 o bimestre, sendo que eles, por terem alcançado sucesso no aprendizado, 


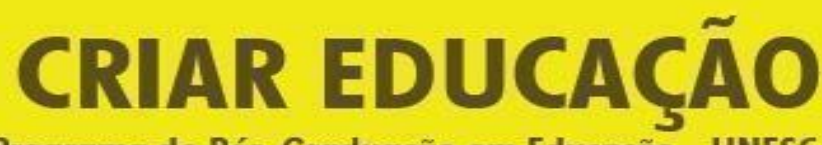

Revista do Programa de Pós-Graduação em Educação - UNESC

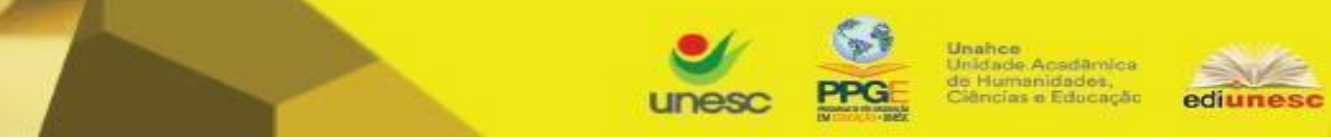

Criar Educação, Criciúma, v. 9, no2, Edição Especial 2020.- PPGE - UNESC - ISSN 2317-2452

gostariam que tal peso fosse maior.

\section{Análise das categorias}

\section{A infraestrutura escolar do ponto de vista dos estagiários}

A infraestrutura do ambiente escolar é um aspecto extremamente relevante no processo de ensino e aprendizagem pensando em seus mais diversos aspectos, seja de mobiliário, de tecnologias, acessibilidade, manutenção etc. Segundo Monteiro e Silva (2015), a sala de aula é um espaço cuja estrutura deve possibilitar o desenvolvimento das atividades escolares e, caso esse ambiente seja precário, 0 processo de ensino e aprendizagem, consequentemente, será prejudicado.

Durante o processo de escolarização na Educação Básica, os sujeitos que colaboraram com essa pesquisa, provavelmente, estudaram em colégios públicos, semelhantes com as escolas onde realizaram o estágio, ou até mesmo, em alguns casos, no mesmo estabelecimento. O julgamento desses estagiários acerca da infraestrutura pode não ser o mais adequado, no sentido de que os alunos que não participaram de determinados espaços e atividades em sua formação enquanto estudantes da Educação Básica, possivelmente não sentiram falta desses ambientes. Com isso, não queremos generalizar as condições das escolas, numa polarização entre públicas e privadas, mas, apenas, reforçar que a realidade vivenciada enquanto estudantes e, agora, estagiários, são muito parecidas.

De maneira geral, três aspectos apontados nos relatos nos chamam a atenção pelo devido destaque dado por dois ou mais estagiários: a) os sujeitos indicam a oferta de uma boa infraestrutura física; b) por outro lado, predomina a característica de espaços escolares fechados, com ausência de ambientes de lazer e convivência estudantil, de árvores etc.; c) apesar da presença de laboratórios voltados para o ensino, tais ambientes não são suficientemente utilizados.

Para E1, E2 e E4, os colégios onde cada um cumpriu o estágio possuía boa estrutura física. E2 relatou a existência de área ampla cercada por árvores e espaços de lazer. E6 afirmou que prevalecem as "áreas de concreto". O pedagogo José Pacheco destaca que, "à luz da produção científica no campo da educação, é 


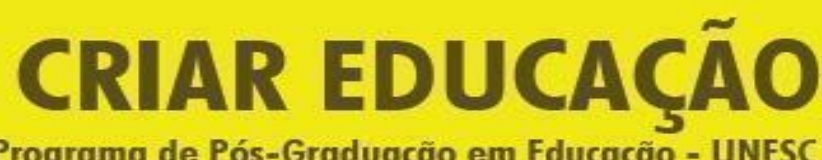

Revista do Programa de Pós-Graduação em Educação - UNESC

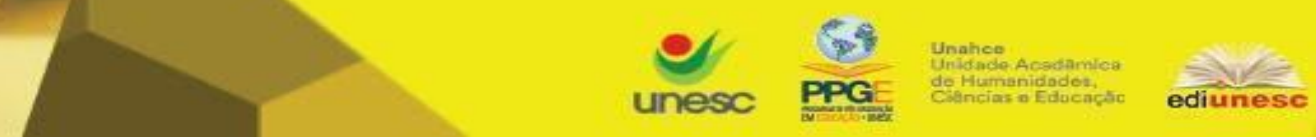

Criar Educação, Criciúma, v. 9, №2, Edição Especial 2020.- PPGE - UNESC - ISSN 2317-2452

descabido manter a expressão 'sala de aula' no discurso pedagógico. Falemos, antes, de espaços de aprendizagem. De espaços de convivência reflexiva, de que as escolas carecem" (REVISTA EDUCAÇÃO'1, 2018, s.p.).

A segurança dos colégios é uma questão também suscitada. E1 relatou que a escola era fechada, e os blocos cadeados para que os alunos não tivessem acesso. Já E3 questionou a segurança do colégio, pois, apesar de haver câmeras posicionadas estrategicamente, o acesso era o mesmo para alunos, professores e outros indivíduos, sendo necessário que as zeladoras vigiassem os portões, que nem sempre estavam trancados. Segundo E2, os portões ficavam sempre abertos, mas existia o serviço de patrulha escolar ofertado pela Polícia Militar do Estado. Somente E4 e E6 afirmaram que o colégio oferecia segurança aos alunos e professores. E6 descreveu que o portão de entrada possuía fechadura eletrônica, e só era aberto no horário de entrada e saída dos alunos.

Nos relatos de Estágio Supervisionado analisados, percebemos precariedade nas instalações e materiais do laboratório de informática, do ponto de vista dos sujeitos. A maioria dos colégios possui laboratório de informática, porém, nem todos os computadores funcionam. Em alguns colégios, a quantidade de computadores não era suficiente para os alunos da turma, impossibilitando os estagiários de usarem o laboratório. De acordo com Rezende e Borges (2017), os professores da Educação Básica se sentem inseguros em fazer uso de recursos tecnológicos nas aulas de Matemática. Os autores também apontam que a falta de computadores e de manutenção nos mesmos é mais um obstáculo que dificulta o uso do Laboratório de Informática.

Apenas E1 e E6 mencionaram a existência de laboratório de ensino de matemática nos colégios. E1 ainda falou da diversidade de recursos pedagógicos disponíveis, dos quais, alguns os professores não sabem utilizar. Lopes e Araújo (2007) defende a existência de laboratórios de ensino de matemática em todas as escolas. Além disso, o autor destaca que, para além da existência do espaço físico, o professor deve receber formação adequada para "[...] saber utilizar corretamente os

\footnotetext{
${ }^{1}$ Artigo jornalístico, sem identificação do autor, retirado da Revista Educação.
} 
materiais didáticos, pois estes, como outros instrumentos [...] exigem conhecimentos específicos de quem os utiliza" (LOPES; ARAÚJO, 2007, p.24).

Alguns dos colégios dispõem de acessibilidade para deficientes. E2, por exemplo, estagiou em um estabelecimento onde existiam rampas de acesso. E4 mencionou que, além das rampas, existiam luzes para indicar o início e término da aula em atenção aos estudantes surdos. Já o colégio onde E3 estagiou não oferecia acessibilidade para deficientes físicos. Cabe destacar que, quando se fala em acessibilidade, não podemos nos prender apenas às adaptações prediais, mas, também, às metodologias de ensino, com destaque para o uso de materiais adaptados, da Libras como língua, dentre outros aspectos. Negrini et al (2010) apontam a acessibilidade como fator não somente de ingresso dos estudantes com necessidades especiais, mas, sobretudo, de permanência. Para eles, "o binômio "acessibilidade-inclusão" é inseparável, implicando qualificação mútua" (p.296). Nesse sentido, há que se considerar também a reflexão e reformulação constante dos currículos escolares e demais documentos que norteiam a prática docente.

Nos relatórios analisados, nota-se a ausência de espaços abertos e projetos destinados às atividades culturais, sendo que somente E3 menciona que o colégio oferece projetos de dança e música no contraturno. Dussel e Caruso (2003), ao refletirem acerca da genealogia da sala de aula, apontam que a escola "não tem nada de natural" (p.32), sendo que todos os aspectos a ela concernentes, e aqui destacamos a infraestrutura e a ausência de espaços de convivência, foram construídos socialmente no decorrer da história. Em outras palavras, as escolas, historicamente, não foram planejadas enquanto espaço de lazer, mas de vigilância.

\section{A tentativa de implementação pelos estagiários de atividades e/ou condutas} diferenciadas das dos professores regentes.

$\mathrm{Na}$ presente categoria, abordaremos as tentativas dos estagiários de implementar atividades diferenciadas daquelas comumente realizadas pelos professores regentes nas turmas participantes. Tais atividades, segundo os licenciandos, são oportunidades de aplicação em sala de aula de discussões teóricas ocorridas na formação inicial, no curso de Licenciatura em Matemática. Não 


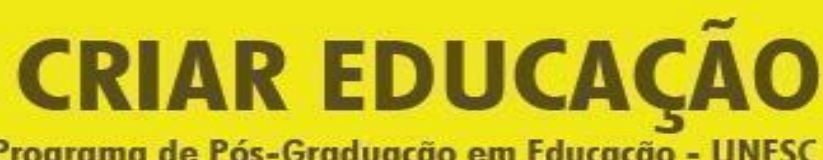

Revista do Programa de Pós-Graduação em Educação - UNESC

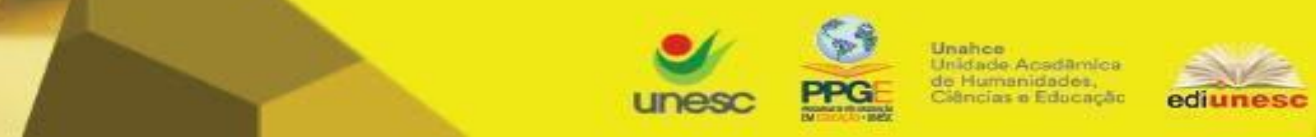

Criar Educação, Criciúma, v. 9, no2, Edição Especial 2020.- PPGE - UNESC - ISSN 2317-2452

queremos, com isso, julgar as práticas dos regentes (esse não é o objetivo do presente texto), mas salientar que o estagiário opta por estratégias que muitas vezes os estudantes não vivenciaram, o que acaba por criar uma relação conflituosa entre estagiários, educandos e professores regentes, interferindo diretamente no ensino e na aprendizagem.

A maioria dos estagiários classificou as aulas ministradas pelos professores regentes como "tradicionais", nas quais o professor passava o conteúdo, apresentava exemplos, e recomendava aos alunos exercícios semelhantes. Além disso, segundo os participantes, o livro didático é o principal, se não o único, instrumento de ensino, dispensando a implementação de aulas diferenciadas. E3 relatou que a professora regente não optou por nenhuma outra metodologia de ensino, mesmo que a usada por ela causava desinteresse nos alunos pela disciplina. Segundo Stahl et al (2011), às dificuldades relacionadas ao aprendizado dos alunos em Matemática podem advir da utilização de aulas expositivas, nas quais os conteúdos seguem um rigor matemático, ou seja, as aplicações práticas dos conceitos são escassas, ou até mesmo, inexistentes.

Com relação às avaliações de aprendizagem, E3 aponta que a prova aplicada pela professora regente era composta somente de cálculos de áreas e volumes, e que os alunos pareciam despreparados para realizar a avaliação. E5 também menciona a falta de segurança nos alunos ao fazer a avaliação, justificando esse fato pelas estratégias didáticas da professora regente.

Diferente dos professores regentes, os estagiários fizeram uso de atividades diferenciadas e que, segundo eles, foram praticadas também nas aulas de estágio na universidade. E1 aplicou duas atividades, uma denominada "o bolo e a matemática", e outra de "Alturas Inacessíveis", na qual os alunos calculavam a altura de um objeto por meio da ferramenta fotografia. E6 elaborou um mapa conceitual acerca de Análise Combinatória que, segundo ela, proporcionou um resultado satisfatório. E4 e E3 relatou que elaboravam problemas envolvendo o cotidiano dos alunos. Na tentativa de E3, em que foi utilizado um problema que simulava um campeonato de futebol, segundo ele, as alunas da turma tiveram dificuldades maiores que os alunos em resolvê-lo, pois não possuíam conhecimento relativo ao assunto. 
E5 também aplicou a atividade do bolo, mas os alunos não quiseram participar. Para ela, tal fato deve-se à adoção de uma metodologia diferente da professora regente. Segundo ela, os alunos estavam acostumados a receber respostas prontas e, quando de sua proposta de intervir apenas após os resultados terem sido apresentados e discutidos, essa conduta não foi aceita pelos estudantes. Como suas opções metodológicas não estavam fornecendo resultados significativos, E5 optou por agir de maneira parecida à professora regente, mesmo que para ela essa metodologia não fosse adequada. A não aceitação da mudança repentina de práticas docentes vivenciadas pelos alunos seria um movimento de resistência inconsciente pelos estudantes. Tal fato se deve, segundo Brousseau (1982), às expectativas dos alunos em relação às práticas docentes, bem como às dos professores em relação aos alunos, denominado pelo autor de "Contrato Didático".

Para Lima e Silva (2016), um dos recursos para tornar a aula mais significativa é a resolução de situações problemas envolvendo assuntos do cotidiano dos alunos. As autoras defendem que o ensino contextualizado permite o aluno compreender 0 porquê de estudar determinando conteúdo, e ainda desperta o interesse do mesmo em aprender aquilo que é útil e eficiente para ele. Rezende e Borges (2017) destacam que, quando os alunos utilizam conceitos em uma atividade prática envolvendo assuntos do cotidiano, os mesmos adquirem uma compreensão desses conceitos, que poderia não ter sido suficiente se fosse trabalho de forma tradicional.

Apenas E1 realizou uma aula no laboratório de informática, com o objetivo de usar o software LibreOfficeCalc. E2 relatou que a professora regente não achava válido o uso do software GeoGebra, tampouco aulas ao ar livre (essas que foram duas estratégias propostas pelos estagiários à regente), alegando que essas aulas tomariam tempo, "atrasando o conteúdo". E4, ao propor à professora regente da turma o uso do Laboratório de Informática pelos estagiários, não obteve sua aceitação. Quanto ao uso de tecnologias, E3 refletiu que deveriam ter usados mais softwares, pois, para ele, o uso desses mecanismos dá liberdade ao aluno e aproxima-o da tecnologia.

Para finalizar tal categoria, e não nos prendermos apenas nas relações conflituosas aqui elencadas, há que se considerar que os sujeitos de nossa pesquisa 
e, de maneira geral, os estagiários de cursos de licenciatura, têm nessa etapa a oportunidade de potencializar uma reflexão crítica acerca de "que professor de matemática eu quero ser", além de "que professor de matemática eu consigo ser". Todos nós crescemos presenciando diretamente práticas docentes, já que passamos boa parte da vida acompanhando uma média de 10 professores por ano de escolarização em atuação. Com isso, a construção do educador deve ser considerada como socialmente dada, que depende de vários momentos: da escolarização, da observação enquanto estagiário, da regência, e das discussões teóricas possibilitadas nas disciplinas dos cursos de licenciatura.

\section{A insegurança dos agentes escolares acerca do estagiário na condição de} regente de aula.

De modo geral, percebemos a predominância de uma visão pelos agentes escolares de que os estagiários seriam incapazes de regerem uma aula de boa qualidade e/ou conseguirem lidar com os estudantes de suas turmas. Justificamos tal categoria, de maneira resumida, por meio de três aspectos por nós levantados: a) a interferência da orientação pedagógica na escolha da turma entendida como "ideal"; b) a não identificação dos estagiários como professores; c) e a intervenção do professor regente durante a aula dos estagiários, com a consequente retirada de suas autonomias. Sakai e Pereira (2017) destacam que, mesmo com a presença de medos, frustrações, inseguranças, conflitos, desafios e tensões durante o período de regência do estágio, esse período ainda se configura como uma experiência de suma importância durante a graduação. Entendemos que as atitudes que se enquadram na presente categoria também são frutos de um distanciamento entre universidade e escola, no sentido de dialogarem conjuntamente acerca do papel do estágio na formação docente inicial e, por conseguinte, da atuação conjunta entre professor regente e estagiário em sala de aula.

O conceito de que estagiários só darão conta de uma turma "ideal", cujos alunos são disciplinados e têm notas acima da média, reflete-se na intervenção da escolha da turma por parte da orientação pedagógica e dos professores do colégio. E3 mencionou que a dupla de estagiários estava disposta a encarar dificuldades como 
indisciplina e notas baixas, pois esses desafios aproximam o estagiário da realidade profissional, mas a orientação pedagógica tentou desencorajá-los. O mesmo aconteceu com $\mathrm{E} 4$, o qual relatou que os terceiros anos não estavam disponíveis, pois a greve tinha atrasado o conteúdo, e para a pedagoga, nesse último ano da Educação Básica é necessário um trabalho específico para o ingresso dos estudantes no Ensino Superior, ou seja, um ensino que priorize a preparação para os exames vestibulares. Ainda no caso de $E 4$, a pedagoga do colégio quis restringir o período de regência dos estagiários, considerando as 20 horas/aula como uma permanência grande com a turma, outro ponto que chama a atenção nesse relato é o fato de alguns professores que não aceitavam estagiários em suas turmas, o que restringiu ainda mais a escolha da classe para cumprir o estágio.

E5 justificou a interferência da orientação pedagógica na escolha da turma à resistência que os alunos têm com estagiários. Ao considerar essa reflexão, percebemos, na maioria dos relatos, que os alunos não identificavam os estagiários como professores. No relato de E2, não houve interação entre estagiários e alunos durante o período de estágio de observação. Em contrapartida, os alunos também conversavam mais entre si quando os estagiários estavam na regência em comparação à atuação do professor da turma. E5 mencionou que os alunos resistiam em deixar a estagiária ajudá-los, e sequer se aproximavam para pedir auxílio. No caso de E3, a professora regente determinou que os alunos não pedissem ajuda dos estagiários durante o período de observação. Ainda, E6 destacou que, mesmo durante a regência dos estagiários, a autoridade pertencia ao professor. Também segundo E6, o professor regente nem a cumprimentava e as estagiárias nunca foram convidadas para entrar na sala dos professores.

Tardif (2007) afirma que é preciso uma lógica de formação profissional que reconheça os futuros professores como sujeitos do conhecimento, e para isso, é preciso proporcionar-Ihes tempo e espaço para que possam atuar de forma autônoma em suas próprias práticas de ensino, na construção de competências necessárias à profissão. Na maioria dos relatos, percebemos que o professor regente intervinha durante a regência dos estagiários para chamar atenção dos alunos, complementar a fala dos estagiários em relação ao conteúdo, ou até mesmo corrigi-los. Alguns 
professores liberavam os alunos para sair da sala sem a intermediação dos estagiários que, naquele momento, conduziam a aula.

Destacamos o relato de E2, no qual a professora determinou que o estágio não fosse realizado simultaneamente entre a dupla, e sim, dividido de forma que cada estagiário ministrasse 10 aulas (o primeiro estagiário daria 10 aulas sem a colaboração do segundo e, ao final dessas 10, o mesmo ocorreria com o segundo estagiário). Para E2, esse tipo de intervenção retirava a autonomia da dupla, e contribuía para que não fossem caracterizados como professores pelos alunos. Lopes et al. (2017) apontam que o Estágio Supervisionado contribui para a construção da identidade docente. Logo, consideramos que, se a autonomia do estagiário for restrita em alguns aspectos relacionados à sua atuação docente, o mesmo pode não desenvolver sua identidade como tal, já que seu espaço para atuar está comprometido. Ainda que a autonomia dos estagiários fora restringida, todos os sujeitos tiveram liberdade para trabalhar o conteúdo em sala de aula, mesmo que os temas tenham sido definidos pelos professores regentes.

Quanto à intervenção do professor regente, entendemos que a mesma deva, sim, ocorrer, porém, fica a tarefa, muitas vezes paradoxal, de permitir certa autonomia aos estagiários e, ao mesmo tempo, contribuir com sua formação, já que, na maioria das aulas, era o regente quem estava junto aos estagiários, e não o orientador. Acreditamos que os professores não devem abrir mão dessa contribuição formativa, contudo, há que se atentar para "em que momentos" e "como" intervir, de modo a não ferir a autonomia docente, característica essa também fundamental para o processo de formação inicial docente.

\section{A necessidade de reformulação nos cursos de graduação para a formação} inicial de professores de Matemática do ponto de vista dos estagiários.

Ao abordarmos essa categoria, pretendemos analisar a necessidade de reestruturação no curso de licenciatura em Matemática da Unespar - Campus Campo Mourão, baseando-nos em aspectos elencados pelos estagiários após vivenciarem o ato de regência de uma turma. De modo geral, nos relatos analisados os sujeitos enfatizam que somente a graduação não é suficiente para formar um professor por 


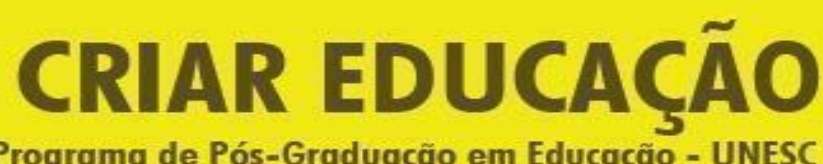

Revista do Programa de Pós-Graduação em Educação - UNESC

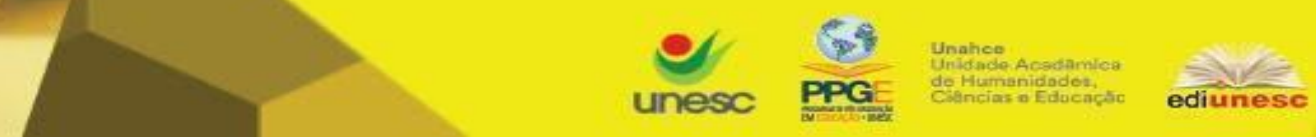

Criar Educação, Criciúma, v. 9, №2, Edição Especial 2020.- PPGE - UNESC - ISSN 2317-2452

completo, e ainda, que o Estágio Supervisionado não permite que o licenciando vivencie plenamente a experiência de ser professor, como descreveremos a seguir mais detalhadamente.

Como discutido na Categoria 3, os estagiários são vistos, em alguns casos, como incapazes de promover um ensino de qualidade, sendo que um dos fatores que contribuem para essa concepção é a ausência da abordagem no Ensino Superior de conteúdos matemáticos tratados na Educação Básica. De acordo com E6, os estagiários precisam ensinar conteúdos que não aprenderam enquanto estudantes da Educação Básica ou até mesmo do Ensino Superior. Como propõe E1, os professores da graduação devem relacionar as disciplinas do Ensino Superior com os conteúdos do Ensino Fundamental e Médio, pois, dos relatos analisados, somente E2 afirmou ter visto na graduação o conteúdo que ensinaria na regência. Como salienta Moreira (2012), saber matemática não é suficiente para a prática docente, é preciso saber muito mais. Com isso, fica a cargo das licenciaturas planejarem um currículo que corresponda aos conhecimentos necessários para docência e sobre a própria escola que é o local de trabalho do futuro professor.

Ao tratar da graduação considerando toda a grade curricular, E6 afirma que a mesma é voltada para a formação de professores de Ensino Superior e não para a Educação Básica. E5 apontou as disciplinas Estágio II, Políticas Educacionais, Modelagem Matemática e Didática da Matemática como as que contribuíram na sua formação como professora e, por outro lado, ela afirma que disciplinas como Cálculo I, Geometrias, Estruturas Algébricas, Equações Ordinárias e Análise da Reta não contribuíram para sua prática de ensino. Já para E3, todas as disciplinas auxiliaram na sua formação, porém, ele enfatiza que somente teoria e didática não formam um professor. Tardif (2007) justifica a importância de repensar a significação das disciplinas da grade curricular para os futuros professores ao fato que as mesmas são concebidas sem possuir relação com o ensino e a realidade da prática docente. Além disso, tais disciplinas são discutidas, em alguns casos, por professores que não possuem interesse pela realidade escolar e pedagógica.

Nos cursos de licenciatura, na maioria das vezes é por meio do Estágio Supervisionado que o licenciando executa a prática docente. Para Sakai e Pereira 


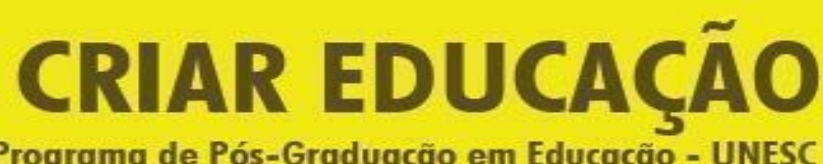

Revista do Programa de Pós-Graduação em Educação - UNESC

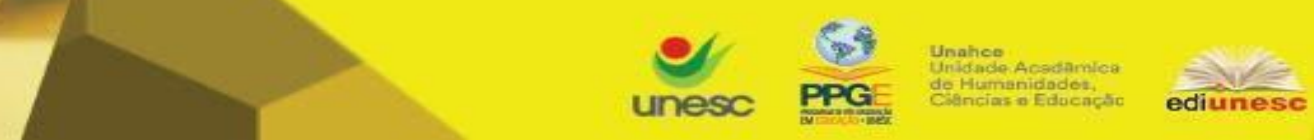

Criar Educação, Criciúma, v. 9, №2, Edição Especial 2020.- PPGE - UNESC - ISSN 2317-2452

(2017), a partir dessa experiência com o fazer docente, os estagiários percebem que somente o conhecimento dos conteúdos curriculares não é suficiente para o exercício da docência. Essa abordagem apresenta-se em nossa pesquisa quando os estagiários em seus relatos promoveram uma discussão acerca das disciplinas de Estágio Supervisionado no curso de Licenciatura em Matemática. Moreira (2012) salienta que os conhecimentos necessários para a docência não se restringem somente aos conhecimentos matemáticos, mas também a um conjunto de saberes que são vinculados à prática de ensinar Matemática, os sujeitos da nossa pesquisa sugeriram que essas disciplinas devem abordar, por meio de leituras e discussões, os problemas que são enfrentados em sala de aula, como indisciplina, dificuldades de aprendizagem, alunos com necessidades especiais, e questões práticas, como preencher o livro de chamada, conselho de classe, elaborar provas e trabalhos, discutir o papel do professor em sala de aula, etc.

Braga (2015) defende que o Estágio Supervisionado não deve ser apenas uma das etapas obrigatórias para a formação do licenciando, mas também promover o crescimento profissional docente e pessoal. Os sujeitos de nossa pesquisa afirmaram que o estágio contribuiu para a formação docente, porém, conforme $\mathrm{E} 3$, as 5 horas de observação e 20 horas de regência não são suficientes para aproximar o estagiário da profissão. Com isso, consideramos necessária a reestruturação das disciplinas de Estágio Supervisionado para os cursos de formação de professores de Matemática, num processo de reflexão conjunta que considera todas as disciplinas da grade curricular. Concordamos com Tardif (2007), que afirma que esses currículos são fragmentados em unidades curtas que não possuem relação entre si, causando pouco impacto aos estudantes.

Desse modo, ponderamos um currículo que propicie ao licenciando aprender a matemática enquanto prática social, voltada para as questões cotidianas. Conforme Fiorentini e Oliveira (2013), dominar esses conhecimentos contribui para que o professor ensine matemática de maneira significativa. Não basta somente o futuro professor dominar os procedimentos matemáticos, mas sim, ser capaz de justificá-los, portanto, não se trata somente de reestruturar os currículos e grades escolares, mas também, de implementar condutas que possibilitem uma visão integradora do curso, 


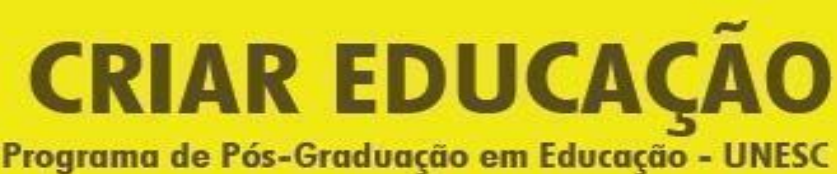

Revista do Programa de Pós-Graduação em Educação - UNESC

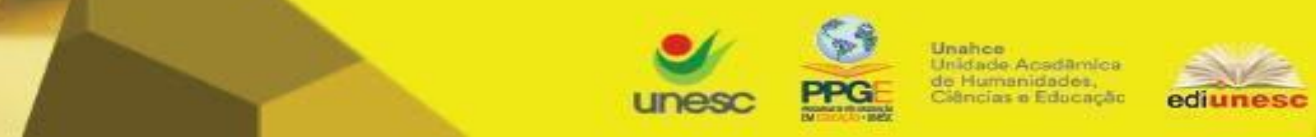

Criar Educação, Criciúma, v. 9, no2, Edição Especial 2020.- PPGE - UNESC - ISSN 2317-2452

não deixando de aprofundar o ensino dos conteúdos específicos. Ainda, podemos considerar a redefinição do currículo proposta por Sakai e Pereira (2017), que defendem a implementação de projetos de pesquisa e práticas coletivas, colaborativas e reflexivas que incentivam o desenvolvimento do futuro docente e dos demais sujeitos envolvidos no processo de formação.

\section{Considerações finais}

Dentre os aspectos observados nos relatos de estágio, predomina uma visão pelos agentes escolares de que os estagiários são incapazes de regerem uma aula de boa qualidade e/ou conseguirem lidar com os estudantes de suas turmas. Devido a essa concepção, alguns professores regentes interferem durante a regência dos estagiários demasiadamente. Percebemos que essa intervenção restringe a autonomia do futuro professor na sala de aula, impossibilitando o desenvolvimento de suas estratégias pretendidas ou, até mesmo, criando resistências e dúvidas quanto à sua intenção profissional futura.

A maioria dos estagiários alegou que os professores regentes optavam por ensinar de maneira tradicional. Desse modo, quando o estagiário seleciona estratégias de ensino que muitas vezes os estudantes não estavam habituados, acaba criando uma relação conflituosa entre estagiários, alunos da turma e professores regentes, o que interfere diretamente no ensino e na aprendizagem. É nesse momento que os estagiários de cursos de licenciatura têm a oportunidade de potencializar uma reflexão crítica acerca de sua identidade docente, questionando a si mesmo sobre que tipo de profissional será quando for professor e quais condutas irá adotar. Acreditamos que esse posicionamento reflexivo e crítico deve ser despertado durante todo ao processo de formação, pois esse tipo de autoavaliação promove o aperfeiçoamento da profissão docente.

Com essa pesquisa, ratificamos o fato de que apenas o curso de Licenciatura em Matemática não é suficiente para formar um professor por completo, e que o Estágio Supervisionado, devido ao tempo limitado de períodos de observação e regência, e as barreiras enfrentadas pelos estagiários, como restrição da autonomia 


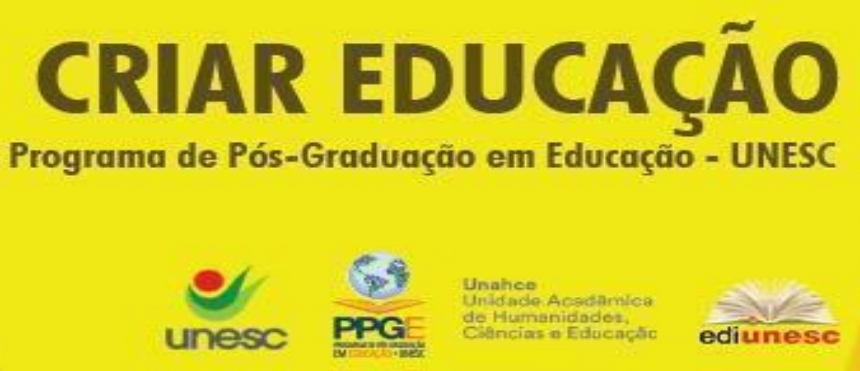

Criar Educação, Criciúma, v. 9, oㅡ, Edição Especial 2020.- PPGE - UNESC - ISSN 2317-2452

para reger a aula, e a não caracterização do estagiário como professor, não permite ao licenciando vivenciar de todo a experiência de ser professor. Deste modo, entendemos como necessária a reestruturação das disciplinas de Estágio Supervisionado nos cursos de formação de professores de Matemática, levando em conta um processo de reflexão conjunta que considera todas as disciplinas da grade curricular.

Por outro lado, nesse movimento de reestruturação, os cursos devem enfocar também uma aproximação maior entre 0 ambiente formativo e 0 de atuação profissional, sempre valorizando um diálogo, o qual não pode ser coibido pela sensação consagrada de que um dos conhecimentos é mais ou menos importante que o outro. Tratam-se de conhecimentos diferentes, objetivos diferentes, mas que devem voltar seus olhares cada vez mais para o mesmo espaço, que é real, ou seja, as salas de aula.

\section{Referências}

BRAGA, J. Estágio supervisionado no programa de formação de professores:

Tensões e reflexões. Revista Eletrônica de Educação, v. 9, n. 1, p. 251-261, 2015.

\section{BRASIL. Diretrizes Curriculares Nacionais para os Cursos de Matemática,} Bacharelado e Licenciatura. Brasília, 2011.

BROUSSEAU, G. Ingéniere didactique. D'un problème à l'étude à priori d'une situation didactique. Deuxième École d'Été de Didactique des mathématiques, Olivet: 1982.

CRUZ, M. A. S.; BITTAR, M. Aula prática reflexiva no Estágio Supervisionado: análise de uma experiência. JIEEM, v. 8(4), p. 43-73, 2015.

DUSSEL, I. CARUSO, M. A invenção da sala de aula: uma genealogia das formas de ensinar. São Paulo: Moderna, 2003.

FIORENTINI, D.; OLIVEIRA, A.T.C.C. O Lugar das Matemáticas na Licenciatura em Matemática: que matemáticas e que práticas formativas?. Bolema, Rio Claro (SP), v. 27, n. 47, p. 917-938, dez. 2013.

FURTADO, S. M. K.; BARAÚNA, K. B.; SOUZA, M. C.; SOUZA, L. O. Uma análise sobre o estágio supervisionado nos cursos de licenciatura da Universidade Federal do Amazonas no munícipio de Itacoatiara-AM. Educação Matemática em Revista, 


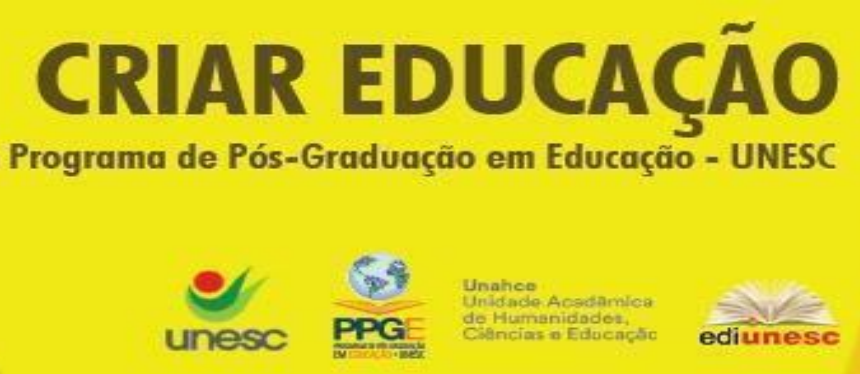

Criar Educação, Criciúma, v. 9, oㅡ, Edição Especial 2020.- PPGE - UNESC - ISSN 2317-2452

Brasília, v. 22, n. 53, p. 17-26, jan./mar. 2017.

LIMA, F. F.; SILVA, R. C. Estágio Supervisionado: práticas inovadoras no ensino de Estatística e Probabilidade no Ensino Fundamental. Revista de Pesquisa Interdisciplinar, Cajazeiras, v. 1, Ed. Especial, 249 - 258, set./dez. 2016.

LOPES, J. A.; ARAUJO, E. A. O Laboratório de Ensino de Matemática: Implicações na Formação de Professores. Zetetiké, v. 15, n. 27, jan. /jun. 2007.

LOPES, A. R. L. V.; PAIVA, M. A. V.; POZEBON, S.; CEDRO, W. L. Estágio Curricular Supervisionado nas licenciaturas em Matemática: reflexões sobre as pesquisas brasileiras. Zetetiké, Campinas, SP, v. 25, n. 1, p. 75-93, jan./abr. 2017.

MONTEIRO, J.S.; SILVA, D. P. A influência da estrutura escolar no processo de ensino-aprendizagem: uma análise baseada nas experiências do estágio supervisionado em Geografia. Geografia Ensino e Pesquisa, v. 19, n. 3, p. 19 - 28, set./dez. 2015.

MORAES, Roque. Análise de conteúdo. Revista Educação, Porto Alegre, v. 22, n. 37, p. 7-32, 1999.

MOREIRA, P. C. $3+1$ e suas (In)Variantes (Reflexões sobre as possibilidades de uma nova

estrutura curricular na Licenciatura em Matemática). Bolema, Rio Claro, SP, v. 26, n. 44, p. 1137-1150, dez. 2012.

NEGRINI, T. et al. Acessibilidade na agenda da inclusão social e educacional.

Revista Educação Especial, Santa Maria, v. 23, n. 37, p. 287-298, maio/ago. 2010.

PIZZANI, L.; SILVA, R. C.; BELLO, S. F.; HAYASHI, M. C. P. A arte da Pesquisa Bibliográfica na busca do conhecimento. Revista Digital de Biblioteconomia e Ciência da Informação, Campinas, v.10, n.1, p.53-66, jul./dez. 2012.

QUADROS, V. C.; KOCHHANN, M. E. R. Contribuições do Estágio Curricular Supervisionado da Licenciatura em Matemática no processo de construção dos saberes docentes dos estagiários. Rencima, v. 9, n. 3, p. 106-122, 2018.

REVISTA EDUCAÇÃO. Como reinventar o tempo e o espaço da escola.

Disponível em: <http://www.revistaeducacao.com.br/como-reinventar-o-tempo-e-oespaco-da-escola/>. Acesso em: 12 de abril de 2018, às 11:05.

REZENDE, V.; BORGES, F. A. O tratamento do tema "vírus da dengue" nas aulas de Matemática com o uso do computador: uma experiência no 6ํano do Ensino Fundamental. C\&D-Revista Eletrônica da FAINOR, Vitória da Conquista, v. 10, n. 1, p. 208 - 223, jan./abr. 2017. 
